\title{
US slashes funds to WHO and other UN agencies
}

IN a pre-recess move that caught administration officials off-guard, the US Congress has made reductions totalling over $\$ 27$ million in next year's contribution to a number of key specialist agencies of the United Nations, including the World Health Organisation (WHO), the Food and Agricultural Organisation (FAO), and the United Nations Educational, Scientific and Cultural Organisation (UNESCO).

Furthermore the Congress has decreed that none of the remaining $\$ 200$ million contributions to these agencies and the UN itself may be used for the purpose of "technical assistance". The agencies are now trying to work out whether they can accept contributions under such conditions; if not, then $25 \%$ of the budget of each which is currently provided by the US, has been placed in jeopardy.

Hardest hit has been WHO, to which the US contribution has been reduced by $43 \%$, or $\$ 20.9$ million; if this cut remains standing, the net result will be a $10 \%$ reduction in the organisation's total budget. Other cuts are: FAO reduced by $\$ 3.2$ million $(10.7 \%$ of the US contribution); UNESCO by $\$ 625,000$ (2.1\% of the contribution): World Intellectual Property Organisation by $\$ 110,000(100 \%$ of contribution); and the UN itself by $\$ 2.85$ million $(2.5 \%$ of total contribution).

The decision to cut the contributions resulted from floor amendments accepted during debates in both the House and the Senate on the budget of the State Department, from which such payments are made. President Carter was unwilling to veto the whole bill, but while signing it into law he said that the amendment "compromises this government's ability to fulfil its legally binding financial obligations"

The President added that he intended to recommend the prompt restoration of the technical assistance funds and eliminate the restrictive language. Administration officials said last week that it was proposed to do this with a supplementary appropriations bill that will be presented as soon as the new Congress meets in January. However, even if the language is changed, it is unlikely that the money will be made available in time to meet the next payments to the agencies, due in February.

The cuts reflect growing concern by some of the more conservative members of Congress over contributions made by the US to international organisations over which they have minimal control; unlike "voluntary" contributions to institutions such as the World Bank, the size of which is related to voting power in the institution. the specialised UN agencies, to which contributions are assessed broadly on grounds of the ability to pay, operate on a one-country-one-vote principle.

"Voluntary" contributions come under the foreign aid bill; and this year Congress has attached to the bill conditions that prohibit its money being spent in countries such as Vietnam and Cuba of whose political regime it disapproves. "Assessed" contributions, however, although paid for out of the State Departments budget, are determined by international agreement, they are not supposed to be subject to the same type of pressures.

In previous years, attempts by members of the Senate to delete the technical assistance money from the department's appropriations and to transfer it to the foreign aid bill have been successfully resisted by the House. This year, however, caught up in the pre-recess rush of legislation, the House voted by 191 to 143 not to reject an amendment added by Senator Jesse Helms, whose cuts and restrictions subsequently passed into law.

"The use of assessed contributions to fund technical assistance is a device to tax the developed nations for the benefit of the undeveloped nations without proper consent from the developed nations", Representative John $\mathrm{H}$. Rousselot, a former official of the right-wing John Birch Society, told the House in supporting the Helms amendment.

"It is changing the very nature of UN agencies away from programmes beneficial to all member nations and towards programmes of special interest to particular areas of the world." David Dickson

\section{Denmark expands research on Ante-natal diagnosis}

THE Danish government has taken a significant step towards including antenatal genetic diagnosis in the general health service. It has approved a plan for expanding laboratories and research centres involved in ante-natal diagnosis and last month granted funds for making it available to all 'risk patients' within approximately five years.

In 1972 the Danish Medical Research Council (MRC) decided to support and coordinate the work of several laboratories on congenital deformities and metabolic diseases. In 1975 the Ministry of the Interior (MI) appointed a committee to investigate the extent to which ante-natal diagnosis should be developed in Denmark, to outline how it should be developed and, finally, to investigate its economics.

The MI-committee presented its report (MI-report 803/1977) in February 1977. It concluded that the community would gain considerably in both human and economic terms if ante-natal diagnosis was given high priority in the general health service.

The report considered chromosomal diseases and inbred metabolic disorders. The MI-committee estimated that about 4.000 chromosomal analyses would be needed yearly to check all risk groups -pregnant women older than 35 and those who have previously given birth to a child with a chromosomal disease. It recommended that seven centres specialising in aminocentesis-which is necessary for chromosomal analysis-be established. At present about 1,000 such analyses are done yearly.

Inbred metabolic disorders are very rare and diagnosis of each illness within this broad category requires its own special technique. Nevertheless, the report mentions several independent calculations which have found that for several specific diseases the benefit of ante-natal diagnosis and abortion in the case of positive results outweighs the cost. The main difficulty, however, lies with identifying those at risk. Either the whole population or selected groups can be screened. At present the Danish population as a whole is screened for phenylketonurea. The MI-committee has recommended that population screening is now extended to include congenital myxodoema.

Any further expansion of population screening for metabolic disorders must await the results of additional research. The MI-committee recommends, however, that programmes for selective screening should be incorporated into a few genetic research centres now. Centres should be established in Copenhagen and Aarhus, it says. They should coordinate all ante-natal biochemical diagnosis in Denmark. Six million kroner should be enough for about 2.000 such analyses a year-the current estimate of the need.

A communication from the National Health Service to all Danish hospitals, medical doctors and midwives marked the initiation of the new programme on 1 Octoher. All pregnant women in Denmark belonging to a risk group are now offered genetic counselling and diagnosis. At the same time the financing of most prenatal genetic diagnosis will pass from the MRC to the general health service.

Sven Erik Godtfredsen 